\title{
THE INFLUENCE OF NUMERICAL VARIABILITY IN SMALL-SIDED GAMES ON YOUTH FOOTBALL GOALKEEPERS’ TACTICAL-TECHNICAL BEHAVIOUR
}

original paper

() Wroclaw University of Health and Sport Sciences

DOI: https://doi.org/10.5114/hm.2022.110125

\section{HONORATO SOUSA ${ }^{1,2 \oplus}$, ÉLVIO R. GOUVEIA ${ }^{1,2,3 \oplus}{ }^{\text {, HUGO SARMENTO }}{ }^{4}$, ROMUALDO CALDEIRA ${ }^{1,2}$, ADILSON MARQUES $^{5,6 \oplus}$, HELDER LOPES $^{1 \oplus}$, ANDREAS IHLE ${ }^{3,7,8}$}

${ }^{1}$ Department of Physical Education and Sport, University of Madeira, 9000-072 Funchal, Portugal

${ }^{2}$ Laboratory of Robotics and Engineering Systems, Interactive Technologies Institute, Funchal, Portugal

${ }^{3}$ Center for the Interdisciplinary Study of Gerontology and Vulnerability, University of Geneva, 1211 Geneva, Switzerland

${ }^{4}$ University of Coimbra, Research Unit for Sport and Physical Activity (CIDAF), Faculty of Sport Sciences and Physical

Education, 3004-504 Coimbra, Portugal

${ }^{5}$ The Interdisciplinary Centre for the Study of Human Performance (CIPER), Faculty of Human Kinetics,

University of Lisbon, 1649-004 Lisbon, Portugal

${ }^{6}$ Instituto de Saúde Ambiental (ISAMB), University of Lisbon, 1649-026 Lisbon, Portugal

${ }^{7}$ Department of Psychology, University of Geneva, 1211 Geneva, Switzerland

${ }^{8}$ Swiss National Centre of Competence in Research LIVES-Overcoming Vulnerability: Life Course Perspectives,

1015 Lausanne, Switzerland

\section{ABSTRACT}

Purpose. The main purpose of this study was to investigate changes in the tactical-technical behaviour of football goalkeepers (GKs) across 5 small-sided games (SSGs) formats with temporary numerical variability.

Methods. The sample involved 4 male under-17 GKs from the same team aged $16.1 \pm 0.52$ years. Three sessions were held on 3 different days to collect information. On each day, the 10-minute SSGs exercise with temporary numerical variability was repeated twice. The numerical ratio of players changed every 2 minutes without interrupting the practice. The exercise always started with a situation of 3 vs. $3+$ GK ('+ GK' for both teams in each format), going through 4 vs. $3+$ GK, 5 vs. $3+\mathrm{GK}, 3$ vs. $4+\mathrm{GK}$, and 3 vs. $5+$ GK.

Results. The 3 vs. $3+$ GK format and the numeric superiority by 1 and 2 ( 4 vs. $3+$ GK and 5 vs. $3+$ GK) induced fewer defensive tasks in comparison with numeric inferiority ( 3 vs. $4+$ GK and 3 vs. $5+$ GK). From an offensive perspective, 3 vs. $3+$ GK caused more offensive tasks in comparison with numeric superiority by 1 and 2 ( 4 vs. 3 + GK and 5 vs. 3 + GK). However, the game formats in numeric inferiority ( 3 vs. $4+$ GK and 3 vs. $5+$ GK) induced more offensive tasks.

Conclusions. This study suggests the use of temporary numerical variability SSGs to increase offensive and defensive GK tactical-technical behaviour.

Key words: football, numerical players variability, defensive tasks, offensive tasks

\section{Introduction}

Small-sided games (SSGs) are adapted and smaller versions of the formal game, designed to increase players' exposure to a specific problem or specific game context, to request adjustments in the intended game behaviours. They are often used in the training pro- cess to authentically recreate the dynamics and reality of an official game, making specific adjustments in the form of task restrictions, manipulated depending on the main objective of the exercise [1-7].

The methodology based on SSGs has grown progressively in terms of its applicability and consequent research related to football. Besides, it is important to

Correspondence address: Élvio Rúbio Gouveia, Department of Physical Education and Sport, University of Madeira, Universidade da Madeira, 9000-390, Funchal, Portugal, e-mail: erubiog@staff.uma.pt, https://orcid.org/0000-0003-0927-692X

Received: March 16, 2021

Accepted for publication: October 17, 2021

Citation: Sousa H, Gouveia ER, Sarmento H, Caldeira R, Marques A, Lopes H, Ihle A. The influence of numerical variability in small-sided games on youth football goalkeepers' tactical-technical behaviour. Hum Mov. 2022;23(4):34-43; doi: https:// doi.org/10.5114/hm.2022.110125. 
understand the potential that these games have to develop simultaneously, both the tactical-technical component and the psychophysiological dimension of the player. This multidimensional potential of SSGs in the players' acute responses makes the popularity of these games very high and leads to their frequent use by coaches of different age groups and competitive levels $[7,8]$.

The representativeness of SSGs, taking into account the formal format of the game, allows keeping the chaotic characteristics of the game, providing a more controllable environment, although without compromising its complexity, dynamic and uncertain nature [9]. Players can deal with a constant repetition of tacticaltechnical actions without actually repeating them, which exposes them to certain task conditions that result in an increase in their perception and awareness of specific behaviours. This training methodology contrasts with training based on analytical situations, characterized by exercises aiming to train skills in isolation [10].

Although there are a large number of experimental studies investigating the impact of different SSGs exposure on physiological responses, as well as on tactical-technical behaviours [2, 6, 11], those were dedicated almost exclusively to the behaviours and actions of the field players. To the best of our knowledge, up to date, no study has examined the impact of SSGs on the role of the goalkeeper (GK), despite its highly complex skill demands [12]. Aiming to identify the main characteristics that top GKs must have, a recent study [13] interviewed 15 'top level' GK coaches and identified good decision making as a central aspect. A question was also asked what a 60-minute GK training session should contain. Interestingly, despite identifying decision making as a key aspect for GKs, most coaches only dedicated $25-30 \%$ of session time to training situations that involved exercises such as SSGs, which effectively develop the decision-making capacity.

This is in line with the idea that the GK training is mostly concentrated on isolated and limited parameters, on responses to the performance of their isolated function in the game itself, such as specific type of movements, skills, and technical requirements [12]. Also, there is a large focus on the assessment of isolated strength performance, namely, in different dimensions of physical fitness (such as strength, power, speed, aerobic capacity, and joint range of motion) and working on injury prevention.

Empirically, the specific requirements of the GK position indicate that the training tends to be largely dedicated to the technical component and predictable technical work. It is usually organized in GK groups (usually 3-4 elements), in small and specifically directed spaces, and separately from the other players, except for finishing workout exercises and SSGs $[14,15]$.

This isolated perspective is highly contradicted by saying that the integration of outfield players into the GK training session is very important and constitutes a current game-changing aspect. Indeed, the incorporation of SSGs in GK training sessions can provide an effective method of manipulating the environment and simulating game contexts, which will expose the GK to experience more situations in training than they would experience in a formal game. This method is also called integrative GK training and aims to overcome the limitations of GK training with small groups of GKs from an isolated perspective. This alternative approach enables to face real game-relevant information and movement couplings, preserving the perspective of repetition without repetition and sustaining an intact player-environment interaction [12].

Altogether, the literature implies that there is a need for further studies on the issues of game performance and tactical-technical development, particularly in GKs - because this player's role has been less studied. On the other hand, currently, it is recognized that the role of the GK is increasingly essential in football, not only in the performance of its defensive functions but also in the offensive process of the team $[16,17]$. Important tactical-technical aspects, such as control of defensive depth or the ability to receive and pass the ball well through different types of passes, are assumed as behaviours increasingly necessary for the good performance of the GK function in the contemporary game dynamics in football [18].

SSGs can allow GKs to deal with a constant repetition of tactical-technical actions without actually repeating them. By exposing them to certain task conditions like in a constantly changing numerical relationship, SSGs will make them develop and increase their perception and awareness of specific behaviours (defensive and offensive), unlike the usual training based on analytical situations and exercises aiming to train skills in isolation. Knowing beforehand that SSGs are a very useful method for introducing offensive and defensive tactical problems, we intended to characterize the authentic GK training experiences in different SSGs conditions. Therefore, we investigated if there was a change in the tactical-technical behaviour of the GK across 5 different SSGs formats with numerical variability ( 3 vs. 3 + GK; 4 vs. 3 + GK; 5 vs. 3 + GK; 3 vs. $4+$ GK; 3 vs. $5+$ GK). 


\section{Material and methods}

Participants

The sample was composed of 4 male under-17 GKs with an average age of $16.1 \pm 0.52$ years. We examined the $4 \mathrm{GKs}$ twice on 3 different days. In total, 24 observations were considered. All participants were federated in the local football association and had been playing in the GK position for at last 5 seasons. They had a regular weekly program of 3 training sessions of 75 minutes each, plus a competitive moment at the end of the week. All the players were informed about the objectives of the research and its requirements, as well as the potential benefits and risks. Participation was voluntary. The subjects' physical characteristics and capacities at baseline are summarized in Table 1.

\section{Study design and procedures}

Throughout the study, 3 sessions were held on 3 different days to collect information. On each day, the 10-minute SSGs exercise was repeated twice. All sessions started at the same time and respected a 24-hour interval between moments of data collection. The SSGs format presented was variable, with a duration of 10 minutes and changing the numerical ratio of players in the game every 2 minutes without interrupting the practice. The exercise always started with a situation of 3 vs. $3+$ GK, going through 4 vs. $3+$ GK, 5 vs. $3+$ GK, 3 vs. $4+$ GK, and 3 vs. 5 + GK (Table 2).

The order in which these changes were applied was randomized differently for the 3 days of investigation (except for the initial 3 vs. $3+$ GK) to maintain uncertainty about the sequence of the situations and to

Table 1. Participants' baseline physical characteristics

\begin{tabular}{lccc}
\hline Physical tests & Mean & $S D$ & $95 \%$ CI for mean \\
\hline Weight $(\mathrm{kg})$ & 74.00 & 7.746 & $61.67-86.33$ \\
Height $(\mathrm{cm})$ & 173.75 & 6.551 & $163.33-184.17$ \\
Body mass index $\left(\mathrm{kg} / \mathrm{m}^{2}\right)$ & 24.625 & 3.6582 & $18.804-30.446$ \\
Bar suspension $(\mathrm{s})$ & 21.8900 & 8.47828 & $8.3992-35.3808$ \\
Sit-ups $(n)$ & 24.25 & 3.304 & $18.99-29.51$ \\
Sit and reach right $(\mathrm{cm})$ & 41.000 & 6.5701 & $30.545-51.455$ \\
Sit and reach left $(\mathrm{cm})$ & 41.375 & 4.4977 & $34.218-48.532$ \\
Sit and reach bilateral (cm) & 39.375 & 5.0229 & $31.383-47.367$ \\
Push-ups $(n)$ & 31.50 & 10.755 & $14.39-48.61$ \\
Hand grip strength, left hand $(\mathrm{kg})$ & 42.075 & 6.2104 & $32.193-51.957$ \\
Hand grip strength, right hand (kg) & 45.600 & 4.8792 & $37.836-53.364$ \\
Flamingo balance test $(n)$ & 11.50 & 5.066 & $3.44-19.56$ \\
Sprint 5 m (s) & 0.9950 & 0.03000 & $0.9473-1.0427$ \\
Sprint $10 \mathrm{~m}(\mathrm{~s})$ & 1.7600 & 0.04320 & $1.6913-1.8287$ \\
Sprint 35 m (s) & 5.1775 & 0.23894 & $4.7973-5.5577$ \\
Yo-Yo Intermittent Recovery Test - Level 1 (s) & 690.00 & 317.280 & $185.14-1194.86$ \\
$t$-test (s) & 9.9650 & 0.26489 & $9.5435-10.3865$ \\
Countermovement jump (cm) & 29.000 & 1.5895 & $27.215-31.985$ \\
Squat jump (cm) & 30.250 & 2.0809 & $26.939-33.561$ \\
\hline
\end{tabular}

Table 2. Description of the SSGs formats

\begin{tabular}{|c|c|c|c|}
\hline Order & $\begin{array}{l}\text { Game format } \\
\text { (A vs. B) }\end{array}$ & $\begin{array}{l}\text { Exercise } \\
\text { timetable }\end{array}$ & Description \\
\hline $1^{\text {st }}$ & 3 vs. $3+$ GK & $0-2 \min$ & Balanced situation \\
\hline $2^{\text {nd } \dagger}$ & 4 vs. $3+$ GK & $2-4 \min$ & 1 element was added to team $\mathrm{A}$, creating numerical superiority of 1 \\
\hline $3^{\mathrm{rd} \dagger}$ & 5 vs. $3+$ GK & $4-6 \min$ & A second element was added to team $\mathrm{A}$, creating numerical superiority of 2 \\
\hline $4^{\text {th } \dagger}$ & 3 vs. $4+\mathrm{GK}$ & $6-8 \mathrm{~min}$ & $\begin{array}{l}2 \text { players were removed from team } A \text { and } 1 \text { element was added to team } B \text {, } \\
\text { creating numerical inferiority of } 1\end{array}$ \\
\hline $5^{\text {th }}+$ & 3 vs. $5+$ GK & $8-10 \mathrm{~min}$ & $\begin{array}{l}\text { Team A kept the same } 3 \text { players and a second element was added to team B, } \\
\text { creating numerical inferiority of } 2\end{array}$ \\
\hline
\end{tabular}

GK - goalkeeper

† The order in which these game formats were implemented was randomized differently for the 3 days of investigation, except for the initial 3 vs. $3+$ GK. 
ensure that there were no conditioning or strategic behaviours on the part of the participants who played the format at its full length. Every 2 minutes, the format was reconfigured by entering (through a zone delimited in the middle of the game space) or removing players (through the nearest line where they were). The original 3 elements of each team that started the 3 vs. $3+$ GK remained throughout the exercise, and the elements that entered always played the same time from day to day. The teams remained the same throughout the study, and the coach's prior knowledge was used for the composition and structuring of the teams, on the basis of the capacities and positions/functions normally performed, in order to equitably distribute individual values, adopting similar strategies and following the recommendations [19].

The dimensions of the game space were $35 \times 25 \mathrm{~m}$, with smaller football goals (6 m wide and $2 \mathrm{~m}$ high). There was a delimited zone for the GKs to be able to grab the ball with their hands. Counting $5 \mathrm{~m}$ from the final line, there were 2 marks in both lateral lines and the area covered all the amplitude of the pitch. All the rules of the game were maintained, except for the rule of the offside, which was removed and ball replacements when the ball crossed the final line were performed by the GK of the team to whom the ball belonged even if it was a corner. In those situations, plus ball replacements in play after goal or goal kicks, the GK had the freedom to follow with the controlled ball by hand or feet unopposed.

To maintain a high intensity and effective playing time, several balls were placed around the field, and staff members strategically placed throughout in those same areas. Coaches were only allowed to provide verbal encouragement feedback and forbidden to give any information or details on strategic issues or tacticaltechnical behaviours. The GKs did not receive any kind of feedback concerning tactical or strategic orientation. They were only asked to perform their function the best they knew and in accordance with the game reality and the rules previously established for the exercise dynamics. The testing sessions started with a 20-minute warm-up, based on a general mobilization of all body segments for a musculoskeletal activation, followed by an exercise to maintain possession of the ball without goals, but including GKs as outside supports, and finally complemented with dynamic stretching and speed exercises. After warming up, the SSGs format lasted for 10 minutes, with 5 minutes of passive rest (that is scientifically proven to allow an effective recovery, both physically and psychologically) between SSGs repetitions [20]) to later perform another series. The sessions ended with a 10-minute return to calm, which consisted of static stretching exercises.

The GK actions (as for the rest of the game action) were recorded with 2 digital cameras from a posterior elevated view, one on the side of the field and another placed at the depth. Data were collected by observing and registering the number of occurrences of the categories previously defined. The observation categories were subdivided into 2 components or performance scores: one covering defensive tasks and the other for offensive ones.

The defensive tasks involved the following categories: (1) body saves: saves with any part of the body except the hands; (2) saves with hands; (3) complete saves: saves after which the ball stayed in possession of the GK, with the subsequent tactical-technical action performed also by the GK; (4) incomplete saves (the opposite of complete saves).

In turn, in the offensive tasks, the following categories were taken into account: (1) receptions: ball control by the GK after a teammate pass; (2) low passes: successfully made by the GK to a teammate; (3) passing with the hands: ball replacements in play or throws after complete saves; (4) high passes: successful passes made by the GK to a teammate, with the ball reaching a height above the ground; (5) ball contacts: the number of foot taps in all offensive actions by the GK.

To complement information and to realize the dimension of the possible number of requests that the formats could impose upon the GK, data about the number of goals and the total number of shots on goal were also recorded, as well as the number of side-shots directed to the bottom line.

\section{Statistical analyses}

First, the Friedman test was used to investigate the difference in the number of defensive and offensive GK tasks across the 5 different SSGs formats with numerical variability ( 3 vs. $3+$ GK; 4 vs. $3+$ GK, 5 vs. 3 + GK; 3 vs. 4 + GK; 3 vs. 5 + GK).

Second, the Wilcoxon signed-rank test was applied to examine the difference in the number of defensive and offensive GK tasks between the game formats (3 vs. 3 + GK versus 4 vs. 3 + GK; 3 vs. 3 + GK versus 5 vs. $3+$ GK; 3 vs. $3+$ GK versus 3 vs. $4+$ GK; 3 vs. $3+$ GK versus 3 vs. $5+$ GK; 4 vs. $3+$ GK versus 5 vs. $3+\mathrm{GK} ; 4$ vs. $3+$ GK versus 3 vs. 4 + GK; 4 vs. $3+$ GK versus 3 vs. $5+\mathrm{GK} ; 5$ vs. $3+$ GK versus 3 vs. $4+\mathrm{GK}$; 5 vs. $3+$ GK versus 3 vs. $5+$ GK; 3 vs. $4+$ GK versus 3 vs. $5+$ GK). Data analysis assumptions were veri- 
fied. The level of confidence was set at 95\%. The data were analysed by using the IBM SPSS Statistics 25 software.

\section{Ethical approval}

The research related to human use has complied with all the relevant national regulations and institutional policies, has followed the tenets of the Declaration of Helsinki, and has been approved by the authors' institutional review board or an equivalent committee (CEIFMH no: 35/2021).

\section{Informed consent}

Informed consent has been obtained from the parents or legal guardians of all individuals included in this study.

\section{Results}

\section{Defensive behaviour}

Table 3 depicts the results of the Friedman test, indicating that in defensive GK tasks, there was a statistically significant difference in body saves $\left[\chi^{2}(4\right.$, $n=24)=10.88, p=0.028]$, hand saves $\left[\chi^{2}(4, n=24)\right.$ $=21.93, p<0.001]$, and incomplete saves $\left[\chi^{2}(4, n=24)\right.$ $=24.94, p<0.001]$ across the different game formats. Considering the mean of the total of defensive tasks, there was a statistically significant difference in the number of actions across the different game formats $\left[\chi^{2}(4, n=24)=21.81, p<0.001\right]$.

The Wilcoxon signed-rank test revealed a statistically significantly lower number of body saves in 4 vs. $3+$ GK in comparison with 3 vs. $4+$ GK $(z=-2.37$, $p=0.018)$. There was also a statistically significantly

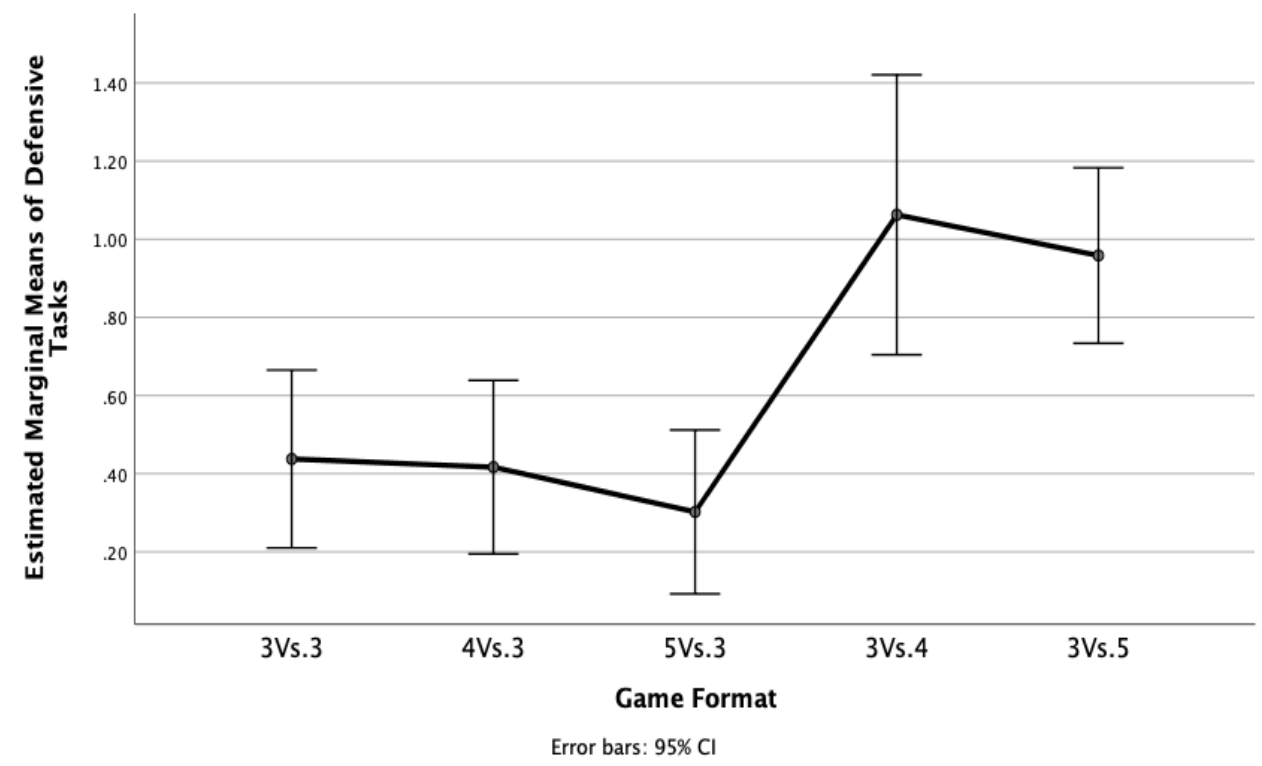

lower number of body saves in 5 vs. $3+$ GK in comparison with 3 vs. $4+$ GK $(z=-2.49, p=0.013)$.

In hand saves, there was a lower number of actions in the 3 vs. $3+$ GK format in comparison with 3 vs. $4+\mathrm{GK}(z=-2.49, p=0.013)$ and with 3 vs. $5+\mathrm{GK}$ $(z=-3.30, p=0.001)$. There was also a lower number of hand saves in 4 vs. $3+$ GK in comparison with 3 vs. $5+\mathrm{GK}(z=-2.59, p=0.010)$. In addition, there was a lower number of hand saves in the 5 vs. $3+$ GK format in comparison with 3 vs. $4+\mathrm{GK}(z=-2.57, p=$ $0.010)$ and with 3 vs. $5+$ GK ( $z=-3.38, p=0.001)$.

Regarding incomplete saves, there was a statistically significantly lower number of actions in the 3 vs. $3+\mathrm{GK}$ format in comparison with 3 vs. $4+\mathrm{GK}(z=-2.90, p$ $=0.004)$ and with 3 vs. $5+\mathrm{GK}(z=-2.60, p=0.009)$. There was also a lower number of incomplete saves in 4 vs. $3+$ GK in comparison with 3 vs. $4+\mathrm{GK}(z=$ $-3.34, p=0.001)$ and with 3 vs. $5+\mathrm{GK}(z=-2.67, p$ $=0.008)$. Finally, there was a statistically significantly lower number of incomplete saves in the 5 vs. $3+$ GK format in comparison with 3 vs. $4+\mathrm{GK}(z=-3.12$, $p=0.002)$ and with 3 vs. $5+\mathrm{GK}(z=-3.02, p=0.003)$.

Considering the mean of the total of defensive tasks, there was a statistically significantly lower number of actions in 3 vs. $3+$ GK in comparison with 3 vs. $4+\mathrm{GK}(z=-2.55, p=0.011)$ and with 3 vs. $5+\mathrm{GK}$ $(z=-2.95, p=0.003)$. There was also a lower number of defensive tasks in the 4 vs. $3+$ GK format in comparison with 3 vs. $4+\mathrm{GK}(z=-3.13, p=0.002)$ and with 3 vs. $5+$ GK $(z=-3.01, p=0.003)$. Finally, there was a statistically significantly lower number of defensive tasks in 5 vs. $3+$ GK in comparison with 3 vs. $4+\mathrm{GK}(z=-2.93, p=0.003)$ and with 3 vs. $5+\mathrm{GK}$ $(z=-3.24, p=0.001)$ (Figure 1).
Figure 1. Graphic representation of all GKs defensive tasks across 5 different small-sided game formats with numerical variability 


\section{Offensive behaviour}

In relation to offensive GK tasks, the Friedman test indicated that there was a statistically significant difference in feet reception $\left[\chi^{2}(4, n=24)=30.36, p<\right.$ $0.001]$, low passes $\left[\chi^{2}(4, n=24)=27.14, p<0.001\right]$, high passes $\left[\chi^{2}(4, n=24)=30.84, p<0.001\right]$, hand passes $\left[\chi^{2}(4, n=24)=17.92, p=0.001\right]$, and feet contacts $\left[\chi^{2}(4, n=24)=45.75, p<0.001\right]$ across the different game formats. Considering the mean of the total of offensive tasks, there was a statistically significant difference in the number of actions across the different game formats $\left[\chi^{2}(4, n=24)=39.79, p<0.001\right]$.

Similarly, the Wilcoxon signed-rank test was used to compare the number of offensive tasks between the different game formats. In the receptions, there was a statistically significantly higher number of actions in 3 vs. $3+$ GK in comparison with 4 vs. $3+\mathrm{GK}(z=$ $-2.98, p=0.003)$ and with 5 vs. $3+\mathrm{GK}(z=-2.86, p=$ $0.004)$. On the other hand, there was a statistically significantly lower number of receptions in the 4 vs. $3+$ GK format in comparison with 3 vs. $4+\mathrm{GK}(z=$ $-2.88, p=0.004)$ and with 3 vs. $5+$ GK $(z=-3.32, p=$ $0.001)$. In addition, there was a statistically significantly lower number of receptions in 5 vs. $3+$ GK in comparison with 3 vs. $4+\mathrm{GK}(z=-3.58, p<0.001)$ and with 3 vs. $5+$ GK $(z=-3.35, p=0.001)$.

Similar results were seen for low passes. There was a statistically significantly higher number of actions in the 3 vs. $3+$ GK format in comparison with 4 vs. $3+\mathrm{GK}(z=-2.95, p=0.003)$ and with 5 vs. $3+\mathrm{GK}$ $(z=-3.10, p=0.002)$. On the other hand, there was a statistically significantly lower number of low passes in 4 vs. $3+$ GK in comparison with 3 vs. $4+$ GK $(z=-3.23, p=0.001)$ and with 3 vs. $5+\mathrm{GK}(z=-2.71$, $p=0.007)$. Also, there was a statistically significantly lower number of low passes in 5 vs. $3+$ GK in comparison with 3 vs. $4+\mathrm{GK}(z=-3.67, p<0.001)$ and with 3 vs. $5+$ GK $(z=-3.40, p<0.001)$.

Regarding high passes, there was a statistically significantly lower number of actions in the 3 vs. $3+$ GK format in comparison with 3 vs. $4+\mathrm{GK}(z=-2.50$, $p<0.013)$ and with 3 vs. $5+\mathrm{GK}(z=-3.07, p<0.002)$. There was also a statistically significantly lower number of high passes in 4 vs. $3+$ GK in comparison with 3 vs. $4+\mathrm{GK}(z=-2.67, p=0.008)$ and with 3 vs. $5+\mathrm{GK}$ $(z=-3.21, p=0.001)$. Finally, there was a statistically significantly lower number of high passes in the 5 vs. $3+$ GK format in comparison with 3 vs. $4+$ GK $(z=-3.05, p=0.002)$ and with 3 vs. $5+\mathrm{GK}(z=-3.35$, $p<0.001$ ).

As for hand passes, there was a statistically significantly higher number of actions in 3 vs. $3+$ GK in comparison with 4 vs. $3+\mathrm{GK}(z=-2.15, p=0.032)$. In turn, there was a lower number of hand passes in 4 vs. $3+$ GK in comparison with 3 vs. $4+\mathrm{GK}(z=-2.46, p=0.014)$ and with 3 vs. $5+$ GK $(z=-2.93, p=0.003)$. Finally, there was a lower number of hand passes in 5 vs. $3+$ GK in comparison with 3 vs. $5+$ GK $(z=-3.01, p=$ $0.003)$.

With reference to feet contacts, there was a statistically significantly higher number of actions in 3 vs. $3+$ GK in comparison with 4 vs. $3+$ GK $(z=-3.61$, $p<0.001)$ and with 5 vs. $3+\mathrm{GK}(z=-3.15, p=0.002)$. On the other hand, there was a statistically significantly lower number of actions in 4 vs. $3+$ GK in comparison with 3 vs. $4+\mathrm{GK}(z=-3.57, p<0.001)$ and with 3 vs. $5+\mathrm{GK}(z=-3.76, p<0.001)$. Finally, there was a lower number of feet contacts in 5 vs. $3+\mathrm{GK}$ in comparison with 3 vs. $4+\mathrm{GK}(z=-4.06, p<0.001)$ and with 3 vs. $5+\mathrm{GK}(z=-4.04, p<0.001)$.

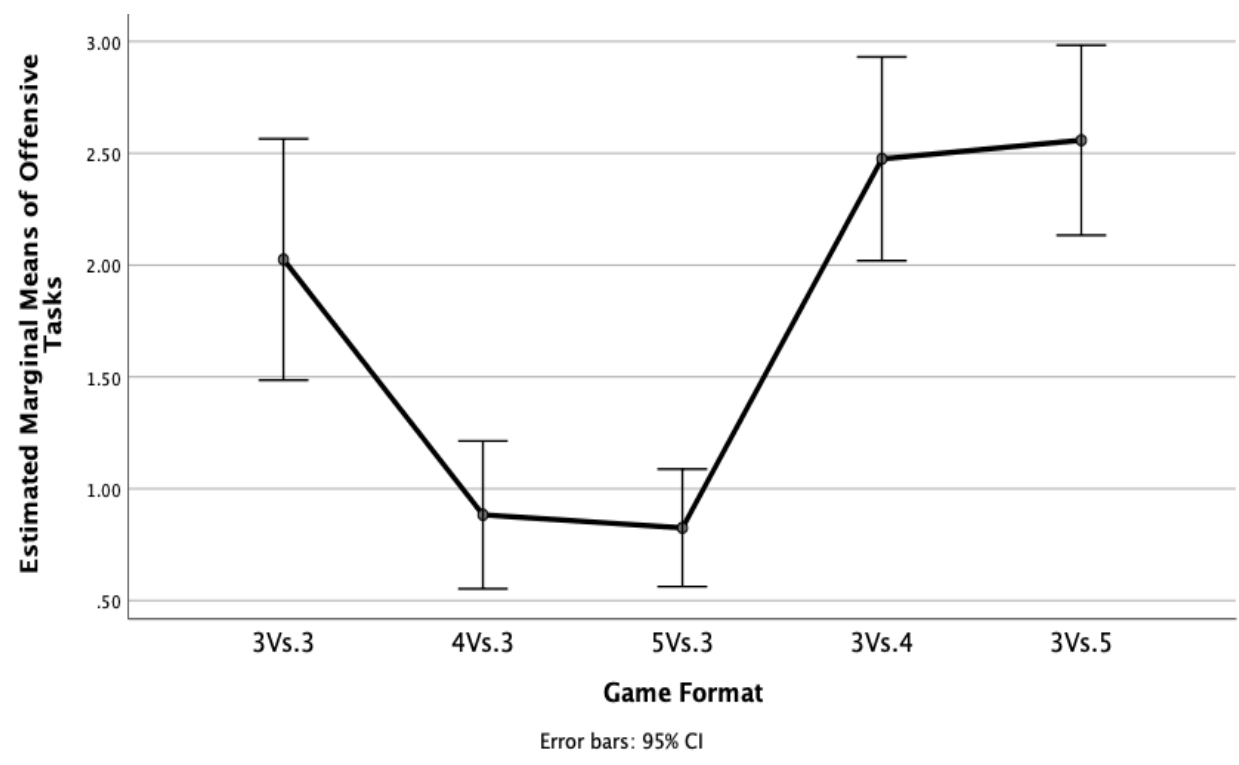

Figure 2. Graphic representation of all GKs offensive tasks across 5 different small-sided game formats with numerical variability 


\section{HUMAN MOVEMENT}

H. Sousa et al., Youth football goalkeepers' tactical-technical behaviour

Table 3. Goalkeeper task differences between different SSGs formats

\begin{tabular}{|c|c|c|c|c|c|c|c|}
\hline \multirow{2}{*}{$\begin{array}{l}\text { Goalkeeper } \\
\text { tasks }\end{array}$} & $\begin{array}{c}3 \text { vs. } 3+\mathrm{GK}(1) \\
(n=24)\end{array}$ & $\begin{array}{c}4 \text { vs. } 3+\mathrm{GK}(2) \\
(n=24)\end{array}$ & $\begin{array}{c}5 \text { vs. } 3+\mathrm{GK}(3) \\
(n=24)\end{array}$ & $\begin{array}{c}3 \text { vs. } 4+\mathrm{GK}(4) \\
(n=24)\end{array}$ & $\begin{array}{c}3 \text { vs. } 5+\mathrm{GK}(5) \\
(n=24)\end{array}$ & \multirow{2}{*}{$p^{\dagger}$} & \multirow{2}{*}{ Difference $\ddagger$} \\
\hline & $\begin{array}{c}\mathrm{M} \pm S D \\
(\text { median } \pm \mathrm{QD})\end{array}$ & $\begin{array}{c}\mathrm{M} \pm S D \\
(\text { median } \pm \mathrm{QD})\end{array}$ & $\begin{array}{c}\mathrm{M} \pm S D \\
(\text { median } \pm \mathrm{QD})\end{array}$ & $\begin{array}{c}\mathrm{M} \pm S D \\
(\text { median } \pm \mathrm{QD})\end{array}$ & $\begin{array}{c}\mathrm{M} \pm S D \\
(\text { median } \pm \mathrm{QD})\end{array}$ & & \\
\hline Body saves & $\begin{array}{c}0.42 \pm 0.93 \\
(0.00 \pm 0)\end{array}$ & $\begin{array}{c}0.17 \pm 0.48 \\
(0.00 \pm 0)\end{array}$ & $\begin{array}{c}0.17 \pm 0.38 \\
(0.00 \pm 0)\end{array}$ & $\begin{array}{c}0.79 \pm 0.98 \\
(0.50 \pm 1)\end{array}$ & $\begin{array}{c}0.42 \pm 0.65 \\
(0.00 \pm 1)\end{array}$ & 0.028 & $\begin{array}{l}2<4 \\
3<4\end{array}$ \\
\hline Hand saves & $\begin{array}{c}0.46 \pm 0.59 \\
(0.00 \pm 1)\end{array}$ & $\begin{array}{c}0.58 \pm 1.02 \\
(0.00 \pm 1)\end{array}$ & $\begin{array}{c}0.33 \pm 0.70 \\
(0.00 \pm 1)\end{array}$ & $\begin{array}{c}1.21 \pm 1.18 \\
(1.00 \pm 2)\end{array}$ & $\begin{array}{c}1.46 \pm 0.98 \\
(1.00 \pm 1)\end{array}$ & $<0.001$ & $\begin{array}{l}1<4 \text { and } 5 \\
2<5 \\
3<4 \text { and } 5\end{array}$ \\
\hline $\begin{array}{l}\text { Complete } \\
\text { saves }\end{array}$ & $\begin{array}{c}0.50 \pm 0.66 \\
(0.00 \pm 1)\end{array}$ & $\begin{array}{c}0.63 \pm 0.92 \\
(0.00 \pm 1)\end{array}$ & $\begin{array}{c}0.46 \pm 0.78 \\
(0.00 \pm 1)\end{array}$ & $\begin{array}{c}0.88 \pm 1.08 \\
(1.00 \pm 1)\end{array}$ & $\begin{array}{c}0.88 \pm 0.95 \\
(1.00 \pm 1)\end{array}$ & 0.305 & $\begin{array}{c}\text { Not } \\
\text { significant }\end{array}$ \\
\hline $\begin{array}{l}\text { Incomplete } \\
\text { saves }\end{array}$ & $\begin{array}{c}0.38 \pm 0.71 \\
(0.00 \pm 1)\end{array}$ & $\begin{array}{c}0.29 \pm 0.69 \\
(0.00 \pm 0)\end{array}$ & $\begin{array}{c}0.25 \pm 0.53 \\
(0.00 \pm 0)\end{array}$ & $\begin{array}{c}1.38 \pm 1.28 \\
(1.00 \pm 2)\end{array}$ & $\begin{array}{c}1.08 \pm 0.93 \\
(1.00 \pm 2)\end{array}$ & $<0.001$ & $\begin{array}{l}1<4 \text { and } 5 \\
2<4 \text { and } 5 \\
3<4 \text { and } 5\end{array}$ \\
\hline Receptions & $\begin{array}{c}1.46 \pm 1.38 \\
(1.00 \pm 2)\end{array}$ & $\begin{array}{c}0.50 \pm 0.88 \\
(0.00 \pm 1)\end{array}$ & $\begin{array}{c}0.38 \pm 0.58 \\
(0.00 \pm 1)\end{array}$ & $\begin{array}{c}1.71 \pm 1.16 \\
(1.00 \pm 2)\end{array}$ & $\begin{array}{c}1.58 \pm 1.21 \\
(1.00 \pm 1)\end{array}$ & $<0.001$ & $\begin{array}{l}1>2 \text { and } 3 \\
2<4 \text { and } 5 \\
3<4 \text { and } 5\end{array}$ \\
\hline Low passes & $\begin{array}{c}2.08 \pm 1.47 \\
(2.00 \pm 2)\end{array}$ & $\begin{array}{c}1.08 \pm 1.28 \\
(1.00 \pm 2)\end{array}$ & $\begin{array}{c}0.88 \pm 0.95 \\
(1.00 \pm 2)\end{array}$ & $\begin{array}{c}2.33 \pm 1.09 \\
(2.00 \pm 1)\end{array}$ & $\begin{array}{c}2.25 \pm 1.19 \\
(2.50 \pm 2)\end{array}$ & $<0.001$ & $\begin{array}{l}1>2 \text { and } 3 \\
2<4 \text { and } 5 \\
3<4 \text { and } 5\end{array}$ \\
\hline High passes & $\begin{array}{c}0.08 \pm 0.28 \\
(0.00 \pm 0)\end{array}$ & $\begin{array}{c}0.04 \pm 0.20 \\
(0.00 \pm 0)\end{array}$ & $\begin{array}{c}0.00 \pm 0.00 \\
(0.00 \pm 0)\end{array}$ & $\begin{array}{c}0.46 \pm 0.59 \\
(0.00 \pm 1)\end{array}$ & $\begin{array}{c}0.71 \pm 0.81 \\
(1.00 \pm 1)\end{array}$ & $<0.001$ & $\begin{array}{l}1<4 \text { and } 5 \\
2<4 \text { and } 5 \\
3<4 \text { and } 5\end{array}$ \\
\hline Hand passes & $\begin{array}{c}2.00 \pm 1.53 \\
(2.00 \pm 2)\end{array}$ & $\begin{array}{c}1.21 \pm 1.32 \\
(1.00 \pm 2)\end{array}$ & $\begin{array}{c}1.58 \pm 1.25 \\
(1.00 \pm 2)\end{array}$ & $\begin{array}{c}2.17 \pm 1.13 \\
(2.00 \pm 2)\end{array}$ & $\begin{array}{c}2.75 \pm 1.59 \\
(2.50 \pm 2)\end{array}$ & 0.001 & $\begin{array}{l}1>2 \\
2<4 \text { and } 5 \\
3<5\end{array}$ \\
\hline Feet contacts & $\begin{array}{c}4.50 \pm 3.71 \\
(4.00 \pm 8)\end{array}$ & $\begin{array}{c}1.58 \pm 2.28 \\
(0.50 \pm 3)\end{array}$ & $\begin{array}{c}1.29 \pm 1.46 \\
(0.50 \pm 3)\end{array}$ & $\begin{array}{c}5.71 \pm 3.24 \\
(5.00 \pm 3)\end{array}$ & $\begin{array}{c}5.50 \pm 3.45 \\
(5.00 \pm 6)\end{array}$ & $<0.001$ & $\begin{array}{l}1>2 \text { and } 3 \\
2<4 \text { and } 5 \\
3<4 \text { and } 5\end{array}$ \\
\hline Goals & $\begin{array}{c}0.79 \pm 0.83 \\
(1.00 \pm 1)\end{array}$ & $\begin{array}{c}0.25 \pm 0.44 \\
(0.00 \pm 1)\end{array}$ & $\begin{array}{c}0.21 \pm 0.41 \\
(0.00 \pm 0)\end{array}$ & $\begin{array}{c}0.96 \pm 0.86 \\
(1.00 \pm 2)\end{array}$ & $\begin{array}{c}1.42 \pm 0.97 \\
(1.50 \pm 1)\end{array}$ & $<0.001$ & $\begin{array}{l}1>2 \text { and } 3 \\
1<5 \\
2<4 \text { and } 5 \\
3<4 \text { and } 5\end{array}$ \\
\hline $\begin{array}{l}\text { Shots } \\
\text { on goal }\end{array}$ & $\begin{array}{c}1.50 \pm 1.10 \\
(1.50 \pm 1)\end{array}$ & $\begin{array}{c}0.83 \pm 0.92 \\
(1.00 \pm 2)\end{array}$ & $\begin{array}{c}0.71 \pm 1.00 \\
(0.00 \pm 1)\end{array}$ & $\begin{array}{c}2.75 \pm 1.36 \\
(3.00 \pm 2)\end{array}$ & $\begin{array}{c}2.92 \pm 1.35 \\
(3.00 \pm 2)\end{array}$ & 0.001 & $\begin{array}{l}1>2 \text { and } 3 \\
1<4 \text { and } 5 \\
2<4 \text { and } 5 \\
3<4 \text { and } 5\end{array}$ \\
\hline $\begin{array}{l}\text { Side-shots } \\
\text { on goal }\end{array}$ & $\begin{array}{c}0.54 \pm 0.72 \\
(0.00 \pm 1)\end{array}$ & $\begin{array}{c}0.42 \pm 0.78 \\
(0.00 \pm 1)\end{array}$ & $\begin{array}{c}0.46 \pm 0.59 \\
(0.00 \pm 1)\end{array}$ & $\begin{array}{c}1.17 \pm 1.24 \\
(1.00 \pm 2)\end{array}$ & $\begin{array}{c}0.96 \pm 1.08 \\
(1.00 \pm 2)\end{array}$ & 0.055 & $\begin{array}{c}\text { Not } \\
\text { significant }\end{array}$ \\
\hline $\begin{array}{l}\text { Defensive } \\
\text { tasks }\end{array}$ & $\begin{array}{c}0.44 \pm 0.54 \\
(0.50 \pm 0.50)\end{array}$ & $\begin{array}{c}0.42 \pm 0.53 \\
(0.38 \pm 0.50)\end{array}$ & $\begin{array}{c}0.30 \pm 0.48 \\
(0.00 \pm 0.50)\end{array}$ & $\begin{array}{c}1.06 \pm 0.85 \\
(0.88 \pm 1.19)\end{array}$ & $\begin{array}{c}0.96 \pm 0.55 \\
(1.00 \pm 1)\end{array}$ & $<0.001$ & $\begin{array}{l}1<4 \text { and } 5 \\
2<4 \text { and } 5 \\
3<4 \text { and } 5\end{array}$ \\
\hline $\begin{array}{l}\text { Offensive } \\
\text { tasks }\end{array}$ & $\begin{array}{c}2.03 \pm 1.34 \\
(1.90 \pm 2.70)\end{array}$ & $\begin{array}{c}0.88 \pm 0.80 \\
(0.60 \pm 0.75)\end{array}$ & $\begin{array}{c}0.83 \pm 0.60 \\
(0.70 \pm 1.10)\end{array}$ & $\begin{array}{c}2.48 \pm 1.08 \\
(2.30 \pm 1.30)\end{array}$ & $\begin{array}{c}2.56 \pm 1.28 \\
(2.50 \pm 1.70)\end{array}$ & $<0.001$ & $\begin{array}{l}1>2 \text { and } 3 \\
2<4 \text { and } 5 \\
3<4 \text { and } 5\end{array}$ \\
\hline
\end{tabular}

$\dagger$ Friedman test, $\ddagger$ difference between game formats assessed by Wilcoxon signed-rank test 
Considering the mean of the total of offensive tasks, there was a statistically significantly higher number of actions in 3 vs. $3+\mathrm{GK}$ in comparison with 4 vs. $3+\mathrm{GK}(z=-3.62, p<0.001)$ and with 5 vs. $3+\mathrm{GK}$ $(z=-3.12, p=0.002)$. In turn, there was a statistically significantly lower number of actions in 4 vs. $3+$ GK in comparison with 3 vs. $4+\mathrm{GK}(z=-3.13, p=0.002)$ and with 3 vs. $5+\mathrm{GK}(z=-3.01, p=0.003)$. Finally, there was a lower number of offensive tasks in 5 vs. $3+\mathrm{GK}$ in comparison with 3 vs. $4+\mathrm{GK}(z=-2.93$, $p=0.003)$ and with 3 vs. $5+$ GK $(z=-3.24, p=0.001)$ (Table 3, Figure 2).

\section{Discussion}

This study aimed to analyse the effect of different SSGs formats with numerical variability on GK tacticaltechnical behaviour. Considering the total of defensive and offensive GK tasks, there was a statistically significant difference in the number of actions across the different game formats studied. Generally, from a defensive perspective, the 3 vs. $3+$ GK format and the numeric superiority by 1 and 2 ( 4 vs. $3+$ GK and 5 vs. $3+$ GK) induced a lower number of defensive tasks in comparison with numeric inferiority (3 vs. 4 + GK and 3 vs. 5 + GK). From an offensive perspective, 3 vs. $3+$ GK generated a higher number of offensive tasks in comparison with numeric superiority by 1 and 2 (4 vs. $3+$ GK and 5 vs. $3+$ GK). However, game formats in numeric inferiority ( 3 vs. $4+$ GK and 3 vs. $5+$ GK) produced a higher number of offensive tasks in comparison with numeric superiority formats.

Besides using different game formats in terms of the number of players involved, our results partially corroborate the previous literature that considered SSGs as a useful exercise with influence on the offensive and defensive technical and tactical actions of the GK. Ortega-Toro et al. [21] found that GK in the 5 vs. $5+$ GK format carried out more defensive and offensive actions than in 8 vs. $8+$ GK. Similar results were also confirmed by Garcia et al. [22] and Di Salvo et al. [23] by showing more touches, saves, kicks, throws goal kicks in the 5 vs. $5+$ GK game format. Along with these results, the present study highlights the number of players as a relevant constraint in SSGs for GK tactical-technical behaviour. In particular, the present study goes forward in the literature because from our results it is possible to assume that the SSGs formats in which the GK is part of the team in permanent numerical inferiority can provide access to more intense training in both dimensions of physical conditioning and tactical-technical behaviours. On the other hand, in an offensive perspective, 3 vs. 3 + GK assumed high relevance to requesting more offensive tasks as well as the game formats in numeric inferiority.

Jara et al. [13] studied the effect of pitch size on technical-tactical GK actions in SSGs and found that when the dimensions of the SSGs were smaller $(32 \times$ $23 \mathrm{~m}$ ), there were more appearances of both defensive and offensive interactions. It was observed that when training GKs to develop tactical concepts in a context similar to a competition, larger pitch areas might contribute to this approach. When the focus of training is physical performance, to provide more intense training, smaller pitch areas can contribute to the goal [24]. Although we kept a similar pitch size $(35 \times 25 \mathrm{~m})$ in our study, the results highlight that coaches can adopt this smaller pitch dimension to have a more intense GK game interaction (offensive and defensive).

The present study followed a unique experimental design to assess the effect of temporary numerical variability on the GK behaviour. To the best of our knowledge, the closest studies in terms of experimental design were developed by Canton et al. [25], who explored how the use of temporary numerical imbalances during SSGs affected the team's exploratory behaviours, and Szwarc and Oszmaniec [26], who, investigating GK actions in futsal, indicated that as a result of the GK participation in the offense (positioning the game at a disadvantage in the attack), there was a probability of increasing offensive efficiency and soliciting more offensive GK tasks. Considering the results of our study and the scarcely available literature on the topic, we may suggest the use of temporary numerical variability, specifically in game formats such as 3 vs. $3+\mathrm{GK}, 3$ vs. $4+\mathrm{GK}$, and 3 vs. $5+\mathrm{GK}$, to increase training dynamics (in the offensive and defensive phases) and develop different adaptive environments to train GK behaviours.

In terms of practical implications, this type of information can help coaches who, in their intervention context, do not have an element in the staff team destined for the exclusive training of GKs, so that they can adapt their exercises to integrate them in the general training process. Still, the same exercise shows the potential to improve different behaviours and tacticaltechnical specificities in various players.

Some limitations should be acknowledged when interpreting our results. The first one is the small sample size (even considering the specificity of the position and the difficulty to obtain samples of a significant number). Secondly, the scarcity of literature on the topic using a similar experimental design limits the discussion of the present results. More longitudinal 
and experimental studies are needed to reinforce the useability of this game format in GK training. This is a central point to better understand the potential that numerical variability has on the action of the GK. Another limitation is that we have no comparison with data collected during real competition. It would be interesting to obtain data about the occurrence of the same tactical-technical actions and behaviours during matches. In future studies, we intend to collect and compare data from game performance with these formats, providing a broader context as for the training preferences required to prepare GKs for competition. We will also aim to analyse the decision making of the GK in SSGs formats, associated with the rate of their participation in the offensive process of a team. Also, maintaining numerical variability, we intend to understand how it blends with the variation of the pitch size and what influence it has on the action of the GK.

\section{Conclusions}

This study confirms changes in the tactical-technical behaviours of the GK across temporary numerical variability in SSGs. In the defensive phase, the game formats in equality and numerical superiority induced a decrease in the number of defensive actions as compared with formats in numerical inferiority. In the offensive phase, the game format in numerical equality exhibited a higher number of offensive tasks when compared with both formats in superiority. Furthermore, both game formats in numerical inferiority resulted in a greater number of offensive and defensive tasks than any of the other formats under analysis. The study suggests the use of temporary numerical variability SSGs to increase offensive and defensive GK tactical-technical behaviour.

\section{Acknowledgements}

The authors would like to thank field team (Tomás Quintal, Marcelo Pestana and Francisco Gouveia) for technical assistance in data collection and management. We are especially grateful to the younger soccer players who took part in this study for their participation and to the Clube Futebol Andorinha from Santo António, Madeira for providing us with the sports facilities to carry out the study. This study is framed in the Maritimo Training Lab Project. The project received funding under application No. M1420-01-0247-FEDER-000033 in the System of Incentives for the Production of Scientific and Technological Knowledge in the Autonomous Region of Madeira - PROCiência 2020. Finally, H.S. and E.R.G., both belonging to the Inter- active Technologies Institute (Portugal), acknowledge support from LARSyS - Portuguese national funding agency for science, research and technology (FCT), Pluriannualfunding 2020-2023 (reference:UIDB/50009/ 2020).

\section{Disclosure statement}

No author has any financial interest or received any financial benefit from this research.

\section{Conflict of interest}

The authors state no conflict of interest.

\section{References}

1. Davids K, Araújo D, Correia V, Vilar L. How small-sided and conditioned games enhance acquisition of movement and decision-making skills. Exerc Sport Sci Rev. 2013;41(3):154-161; doi: 10.1097/JES.0b013e318292 f3ec.

2. Silva P, Aguiar P, Duarte R, Davids K, Araújo D, Garganta J. Effects of pitch size and skill level on tactical behaviours of association football players during smallsided and conditioned games. Int J Sports Sci Coach. 2014;9(5):993-1006; doi: 10.1260/1747-9541.9.5.993.

3. Olthof SBH, Frencken WGP, Lemmink KAPM. The older, the wider: on-field tactical behavior of elite-standard youth soccer players in small-sided games. Hum Mov Sci. 2015;41:92-102; doi: 10.1016/j.humov.2015.02.004.

4. Travassos B, Silva P, Duarte R, Vilar L, Esteves PT. Manipulating goal posts significantly impacts on tactical behaviours in small-sided football games. In: Furley P, Fasold F, Hüttermann S, Klein-Soetebier T, Kreitz C, Noel B, et al. (eds.), Just play it - "Innovative, international approaches to games”. Hamburg: Feldhaus, Ed. Czwalina; 2016.

5. Arrieta P, Castellano J, Guridi I, Echeazarra I. Effects of a program based on small-sided games on the physical condition in young football players [in Spanish]. Rev Int Cienc Deporte. 2017;13(50):370-380; doi: 10.5232/ ricyde2017.05004.

6. Sarmento H, Clemente FM, Harper LD, da Costa IT, Owen A, Figueiredo AJ. Small sided games in soccer a systematic review. Int J Perform Anal Sport. 2018; 18(5):693-749; doi:10.1080/24748668.2018.1517288.

7. Clemente FM, Afonso J, Sarmento H. Small-sided games: an umbrella review of systematic reviews and metaanalyses. PLoS One. 2021;16(2):e0247067; doi: 10.1371/ journal.pone.0247067.

8. Hill-Haas SV, Dawson B, Impellizzeri FM, Coutts AJ. Physiology of small-sided games training in football: a systematic review. Sports Med. 2011;41(3):199-220; doi: 10.2165/11539740-000000000-00000.

9. Serra-Olivares J, Clemente FM, González-Víllora S. Tactical expertise assessment in youth football using representative tasks. SpringerPlus. 2016;5(1):1301; doi: 10.1186/s40064-016-2955-1. 
10. Tan CWK, Chow JY, Davids K. 'How does TGfU work?’: examining the relationship between learning design in TGfU and a nonlinear pedagogy. Phys Educ Sport Pedagog. 2012;17(4):331-348; doi: 10.1080/17408989. 2011.582486.

11. Sarmento H, Clemente FM, Araújo D, Davids K, McRobert A, Figueiredo A. What performance analysts need to know about research trends in association football (2012-2016): a systematic review. Sports Med. 2018; 48(4):799-836; doi: 10.1007/s40279-017-0836-6.

12. Otte FW, Millar S-K, Klatt S. How does the modern football goalkeeper train? - An exploration of expert goalkeeper coaches' skill training approaches. J Sports Sci.2020;38(11-12):1465-1473; doi: 10.1080/02640414. 2019.1643202.

13. Jara D, Ortega E, Gómez M-Á, de Baranda PS. Effect of pitch size on technical-tactical actions of the goalkeeper in small-sided games. J Hum Kinet. 2018;62(1):157166; doi: 10.1515/hukin-2017-0167.

14. Seaton M, Campos J. Distribution competence of a football clubs goalkeepers. Int J Perform Anal Sport. 2011;11(2):314-324; doi: 10.1080/24748668.2011. 11868551.

15. White A, Hills SP, Cooke CB, Batten T, Kilduff LP, Cook CJ, et al. Match-play and performance test responses of soccer goalkeepers: a review of current literature. Sports Med. 2018;48(11):2497-2516; doi: 10.1007/s40279-018-0977-2.

16. De Baranda PS, Ortega E, Palao JM. Analysis of goalkeepers' defence in the World Cup in Korea and Japan in 2002. Eur J Sport Sci. 2008;8(3):127-134; doi: 10.1080/17461390801919045.

17. Liu H, Gómez MA, Lago-Peñas C. Match performance profiles of goalkeepers of elite football teams. Int J Sports Sci Coach. 2015;10(4):669-682; doi: 10.1260/ 1747-9541.10.4.669.

18. Szwarc A, Lipińska P, Chamera M. The efficiency model of goalkeeper's actions in soccer. Balt J Health Phys Act. 2010;2(2):132-138; doi: 10.2478/v10131-0013-x.

19. Casamichana D, Castellano J. Time-motion, heart rate, perceptual and motor behaviour demands in smallsides soccer games: effects of pitch size. J Sports Sci. 2010;28(14):1615-1623; doi: 10.1080/02640414.2010. 521168.

20. Köklü Y, Alemdaroğlu U, Özkan A, Koz M, Ersöz G. The relationship between sprint ability, agility and vertical jump performance in young soccer players. Sci Sports. 2015;30(1):e1-e5; doi: 10.1016/j.scispo.2013. 04.006 .

21. Ortega-Toro E, García-Angulo A, Giménez-Egido J-M, García-Angulo FJ, Palao J. Effect of modifications in rules in competition on participation of male youth goalkeepers in soccer. Int J Sports Sci Coach. 2018;13(6): 1040-1047; doi: 10.1177/1747954118769423.

22. Garcia JD-C, Refoyo Román I, Calleja-González J, Dellal A. Quantification and analysis of offensive situations in different formats of sided games in soccer. $\mathrm{J}$
Hum Kinet. 2014;44(1):193-201; doi: 10.2478/hukin2014-0125.

23. Di Salvo V, Benito PJ, Calderón FJ, Di Salvo M, Pigozzi F. Activity profile of elite goalkeepers during football match-play. J Sports Med Phys Fitness. 2008;48(4): 443-446.

24. Jara D, Ortega E, Gómez-Ruano M-Á, Weigelt M, Nikolic B, de Baranda PS. Physical and tactical demands of the goalkeeper in football in different small-sided games. Sensors. 2019;19(16):3605; doi: 10.3390/s191 63605.

25. Canton A, Torrents C, Ric A, Gonçalves B, Sampaio J, Hristovski R. Effects of temporary numerical imbalances on collective exploratory behavior of young and professional football players. Front Psychol. 2019;10: 1968; doi: 10.3389/fpsyg.2019.01968.

26. Szwarc A, Oszmaniec M. A model of the efficiency of goalkeepers' actions in futsal. Hum Mov. 2020;21(4): 44-53; doi: 10.5114/hm.2020.95990. 